\title{
Preliminary Investigations of an Oil Based Ethephon Mixture (Motex Plus) on Low Intensity Harvesting Systems of Rubber
}

\author{
Kudaligama K.V.V.S.", Rodrigo V.H.L., Randunu R.P.S. and Rodrigo R.D.J. \\ Rubber Research Institute, Agalawatta, Sri Lanka \\ *vskudaligama@yahoo.com
}

\begin{abstract}
Low intensity harvesting ( $\mathrm{LIH})$ systems facilitate to reduce the cost of production (COP) through the reduction in the cost of tapping and also to minimise the harvester requirement in rubber plantations. In addition, considerable financial benefits are expected due to the increase in economic lifespan of trees caused by the reduction in bark consumption. To compensate the yield loss due to lowering the intensity, 2-Chloroethylphosponic acid (ethephon) is used as a yield stimulant in LIH to enhance the yield per tapping. All commercial formulations of ethephon available in Sri Lanka have been water based. Although such formulations have an advantage in preparing different dilutions by mixing with water, their long term effectiveness in field application are often questionable. A new oil based formulation (Motex plus) has been introduced to Sri Lanka and therefore, the study recorded here was focused to assess its effectiveness in application of LIH.
\end{abstract}

Performance of three low intensity systems recommended in Sri Lanka i.e. S/2 d3 (half spiral based once in three days harvesting), $\mathrm{S} / 2 \mathrm{~d} 4$ (half spiral based once in four days harvesting), and $\mathrm{S} / 4 \mathrm{~d} 3$ (quarter spiral based once in three days harvesting) was tested with application of $2.5 \%$ Motex Plus, every two months interval except during wintering, monthly and every two weeks intervals, respectively together with $\mathrm{S} / 2 \mathrm{~d} 2$ (half spiral based once in two days harvesting) system for comparison. Dry rubber content of latex in LIH systems were above $35 \%$ whilst it was about $33 \%$ in $\mathrm{S} / 2$ d2 system. Yield per tree per year in $\mathrm{S} / 2 \mathrm{~d} 3, \mathrm{~S} / 2 \mathrm{~d} 4$ and $\mathrm{S} / 4 \mathrm{~d} 3$ systems were $5.69 \mathrm{~kg}, 5.48 \mathrm{~kg}$ and $6.19 \mathrm{~kg}$, respectively showing a slight higher yield over the $\mathrm{S} / 2 \mathrm{~d} 2$ system. Therefore potential reduction in the dose of oil based formulation is also discussed. Number of trees affected with tapping panel dryness was comparably lower in LIH systems. Although the bark consumption per tapping was slightly higher in LIH systems, overall bark consumption has dramatically been reduced due to lesser number of tapping days.

Keywords: Ethephon, Low intensity harvesting, Motex plus 